\title{
STRUCTURE AND PROPERTIES OF ADDITIVELY MANUFACTURED WE43 MAGNESIUM ALLOY
}

\author{
${ }^{1}$ Patrícia KRIŠTOFOVÁ, ${ }^{1}$ Jiř́ KUBÁSEK, ${ }^{1}$ Michaela ROUDNICKÁ, ${ }^{1}$ Alena MICHALCOVÁ, \\ ${ }^{2} J a n$ SUCHÝ, ${ }^{2}$ David PALOUŠEK, ${ }^{1}$ Dalibor VOJTĚCH
}

${ }^{1}$ UCT - University of Chemistry and Technology, Prague, Czech Republic, EU

Patricia.Kristofova@vscht.cz

${ }^{2}$ BUT - Brno University of Technology, Brno, Czech Republic, EU

https://doi.org/10.37904/metal.2019.936

\begin{abstract}
The experiment described in this article deals with the comparison of structures and mechanical properties of the Mg-4Y-3RE-0.5Zr (WE43) magnesium alloy produced by three different methods. A technique of additive manufacturing, selective laser melting (SLM), is compared with two conventional manufacturing techniques, casting and extrusion. Microstructures and chemical composition of present phases were studied using scanning electron microscopy (SEM) and energy dispersive X-ray spectrometry (EDS). Mechanical properties were compared based on hardness measurement, compression test and three-point flexural test. Significant differences were found between the microstructures of WE43 alloy produced by different production processes. Measurements of mechanical properties showed similar mechanical properties of additively manufactured samples with as-cast samples
\end{abstract}

Keywords: Magnesium alloy, casting, extrusion, 3D printing, mechanical properties, microstructure

\section{INTRODUCTION}

Magnesium alloys are ones of the most used alloys due to its low density and good mechanical strength, especially in the automotive and aerospace industries. The mostly used $\mathrm{Mg}$ alloys contain $\mathrm{Al}$ and $\mathrm{Zn}$ as essential alloying elements. The main drawback of the Mg-Al-Zn alloys (AZ types) is a low mechanical stability at elevated temperatures above $150{ }^{\circ} \mathrm{C}$. To overcome this drawback, Mg-RE alloys have been developed which are able to withstand temperatures up to $250^{\circ} \mathrm{C}$ and more. In these alloys, stable Mg-RE precipitates are formed that hinder dislocation motion at higher temperatures [1,2]. Mg-4Y-3RE-0.5Zr alloy, known as WE43, was chosen for this experiment. This alloy is known for it's a good thermal stability, high strength, good corrosion resistance and biocompatibility [3].

Additive manufacturing (also known as $3 \mathrm{D}$ printing) is a modern method of producing structurally complex parts that are almost impossible to produce by conventional means [4]. One method of 3D printing is Selective Laser Melting (SLM) where atomized powders are consolidated by the action of a laser beam. A powder is deposited onto a working plate to form a layer, several tens of micrometers thin. The powder layer is then selectively scanned by in each cycle, the working plate is lowered down by one-layer thickness and a new powder layer is deposited $[1,5,6]$. Due to high energy directed to a small volume of material, very high temperature gradients and so cooling rates arise, resulting in very fine-grained microstructures. Cooling speed can reach values up to $10^{3}-10^{6} \mathrm{C} / \mathrm{s}[7,8]$.

Due to the fact that $3 \mathrm{D}$ printing of magnesium alloys is a relatively new process, this paper is focused on describing the microstructure and mechanical properties of the SLM WE43 alloy, and comparison with wellknown processes of casting and extrusion. 


\section{EXPERIMENTAL SETUP}

\subsection{Specimens preparation}

The subject of this work is a 3D printed WE43 magnesium alloy produced by the selective laser melting (SLM) technology. The same alloy produced conventionally, by casting and extrusion, served as a reference material. All compared materials were of the same composition Mg-4Y-3RE- $0.5 \mathrm{Zr}$. The $3 \mathrm{D}$ printed material was produced by an SLM Solution $280^{\mathrm{HL}}$ (SLM solutions AG) machine equipped with $400 \mathrm{~W}$ ytterbium fiber laser, in cooperation with Brno University of Technology. All parameters of the SLM process are shown in Table 1. The samples were printed from a fine gas-atomized powder (30-60 $\mu \mathrm{m}$, Luxfer Mel Technologies) in the form of blocks $80 \mathrm{~mm} \times 10 \mathrm{~mm} \times 2 \mathrm{~mm}$ in size. The longest side was parallel to the working plate. Scanning strategy were stripes, with the change of scanning direction by $67^{\circ}$ each layer.

The cast material was purchased from an industrial manufacturer in the form of an ingot. Further, as-cast ingots were cut into cylinders of $30 \mathrm{~mm}$ in diameter and $60 \mathrm{~mm}$ in length and subjected to a hot-extrusion. The extrusion was carried out at $400{ }^{\circ} \mathrm{C}$, with an extrusion rate of $2 \mathrm{~mm} / \mathrm{s}$ and extrusion ratio of 16 . The resulting extruded rod had a diameter of $7.5 \mathrm{~mm}$.

Table 1 SLM parameters

\begin{tabular}{|l|c|l|c|}
\hline Laser power & $225 \mathrm{~W}$ & Atmosphere & Argon \\
\hline Scanning speed & $450 \mathrm{~mm} / \mathrm{s}$ & Overpressure & $1.2-2 \mathrm{kPa}$ \\
\hline Hatching distance & $90 \mu \mathrm{m}$ & Oxygen level & $0.1-0.3 \%$ \\
\hline Layer thickness & $50 \mu \mathrm{m}$ & Built plate temp. & $120^{\circ} \mathrm{C}$ \\
\hline
\end{tabular}

\section{a. Microstructure characterization}

For microstructural characterization, a we used a standard metallographic procedure consisting of grinding on $\mathrm{SiC}$ papers, polishing on diamond pastes and final polishing on silica suspension Etosil E. Microstructures were observed using a light metallographic microscope OLYMPUS PME 3 and a TESCAN VEGA-3 LMU scanning electron microscope (SEM) equipped with energy-dispersive X-ray spectroscopy (EDS) analyzer Oxford instruments INCA 350.

\section{b. Mechanical properties}

The mechanical properties were compared based on hardness measurement, compression tests and threepoint flexural tests. Hardness was measured by the Vickers method using a Future-Tech FM-700 microhardness tester with a load of $100 \mathrm{~g}$ at a dwell of $10 \mathrm{~s}$. Three-point bending tests and compression tests were performed with the LabTest 5.250SP1-VM universal loading machine. Three measurements were done for each material. For bending, beam test specimens ( $3 \mathrm{~mm} \times 5 \mathrm{~mm} \times 18 \mathrm{~mm}$ ) were used, placed on two supports and the force was applied to the testing body midway between the supports (three-point bending). For compression tests specimens $(7 \mathrm{~mm} \times 7 \mathrm{~mm} \times 7 \mathrm{~mm})$ were used.

\section{RESULTS AND DISCUSSION}

\subsection{Microstructure}

The microstructures of the WE43 alloy are shown in Figure 1. The microstructure of as-cast alloy (Figure 1A) is composed of $\alpha-M g$ dendrites and eutectics predominantly formed by $\alpha-M g+\beta-M g{ }_{14} \mathrm{Nd}_{2} Y$ phase. The average thickness of dendritic branches achieves almost $50 \mu \mathrm{m}$. The microstructure of the sample after the extrusion is shown in Figure 1B. The eutectic network was broken by the extrusion so that the intermetallic 
phase fragmented into very fine particles arranged in parallel in the direction of extrusion can be observed. Also, recrystallization and grain refinement took place. Figures 1C and 1D show the microstructure produced by SLM. The SLM material has extremely fine microstructure, with very fine dendrites of $\alpha-M g$ and interdendritic network enriched in the alloying elements. The dendritic structure can only be observed at high magnification (Figure 1D). Due to the high affinity of magnesium to oxygen, oxide shells are abundant in the microstructure. These oxides shells can prevent the powder particles from a complete fusion. Therefore, original particles of the powder randomly distributed in the material can be found (Figure 1C).
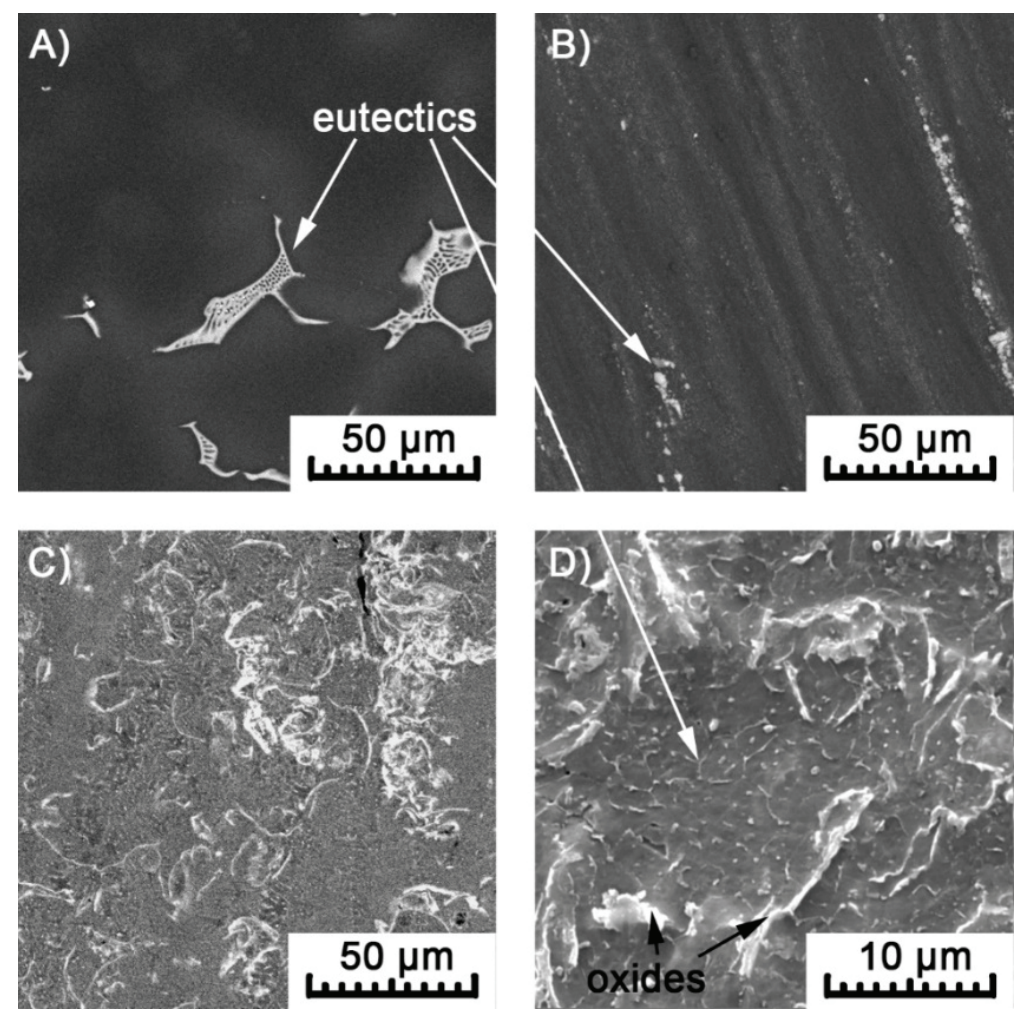

Figure 1 Microstructures of the WE43 alloy: A) as-cast, B) hot-extruded, C, D) 3D printed by SLM

\subsection{Mechanical properties}

Despite significantly finer microstructure, 3D printed WE43 alloy did not show unambiguously the best mechanical behavior. Due to improper consolidation (presence of porosity) and high amount of oxides, the flexural strength remained comparable to the as-cast material (see curves in Figure 2, values in Table 2). Hot extruded samples performed the best thanks to the recrystallization, grain refinement, fragmentation of eutectics and lack of porosity. Only under compression, where internal defects play significantly lower effect, the fine 3D printed structure manifested. The 3D printed samples reached ultimate strength of $441 \mathrm{MPa}$, about $100 \mathrm{MPa}$ more than the as-cast samples and $38 \mathrm{MPa}$ more than the extruded samples. The representative stress-strain curves are compared in Figure 3.

Table 2 Comparison table of mechanical properties of WE43 alloy produced by different methods

\begin{tabular}{|l|c|c|c|}
\hline & Casting & Hot extrusion & 3D printing \\
\hline HV0.1 & 97 & 132 & 86 \\
\hline Flexural strength (MPa) & 221 & 398 & 219 \\
\hline Ultimate compressive strength (MPa) & 341 & 403 & 441 \\
\hline
\end{tabular}




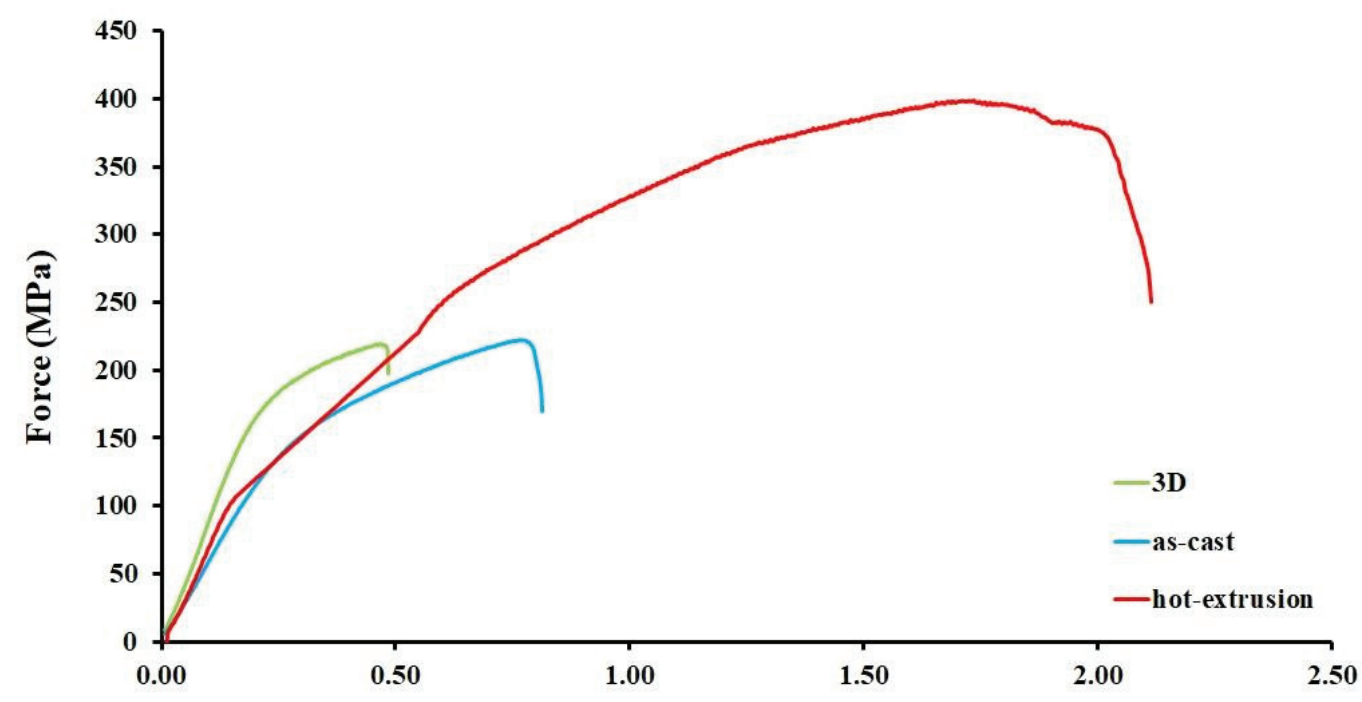

Displacement (mm)

Figure 2 Three-point bending load-dispalcement curve

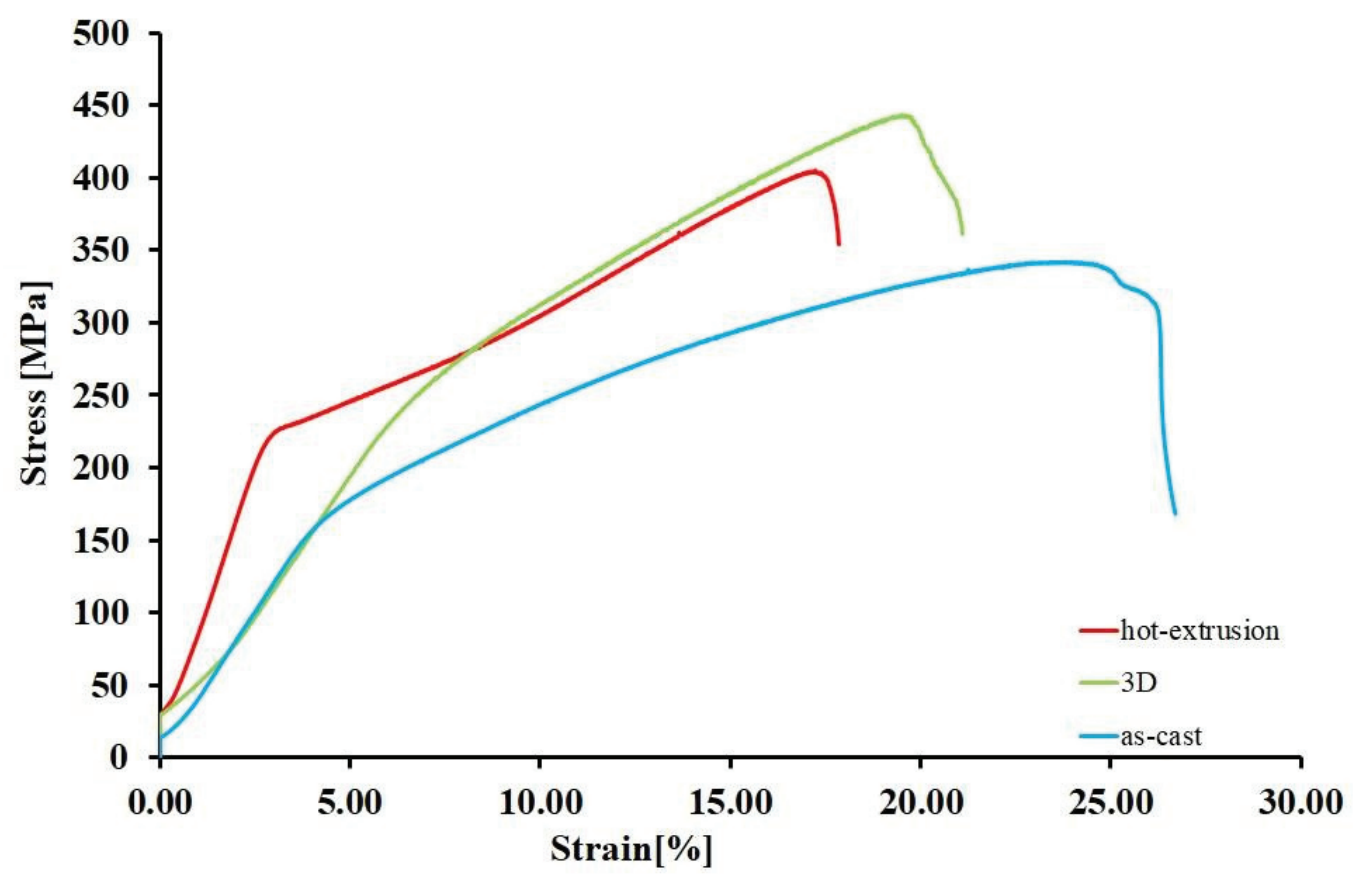

Figure 3 Compression stress-strain curves

\section{CONCLUSION}

Based on the comparison of the microstructure and mechanical tests carried out for 3D printed (SLM), as-cast and hot-extruded WE43 alloy, the following conclusions can be drawn. Microstructure differs significantly according to the production process. Extremely fine microstructure of the 3D printed material can be attributed to very high cooling rates during SLM. However, non-ideal processing atmosphere in SLM with oxygen residues yields in the presence of oxides and imperfect consolidation. As a result, the 3D printed WE43 alloy 
performs similarly to the as-cast material, worse that the hot-extruded material. Only under compression, the $3 \mathrm{D}$ printed alloy surpassed the hot-extruded alloy by $38 \mathrm{MPa}$.

\section{ACKNOWLEDGEMENTS}

\section{Authors wish to thank the specific university research (MSMT No 21-SVV/2019) for the financial support of this research.}

\section{REFERENCES}

[1] HRIVŇÁK, I. and HRIVŇÁKOVÁ., D. Materialography. Ed. 1. 2011, Bratislava: STU.

[2] KRIŠTOFOVÁ, P., KUBÁSEK, J., VOJTĚCH, D., PALOUŠEK, D. and SUCHÝ, J. Microstructure of the Mg-4Y3RE-Zr (WE43) Magnesium Alloy Produced by 3D Printing. Manufacturing Technology. 2019. vol. 19, no. 1, pp. 89-94.

[3] DOBATKIN, S. V., EKATERINA, D. LUKVANOVA, MARTVENKO, N., ANISIMOVA, Y., KISELEVSKIY, M. V, GORSHENKOV, M., YURCHENKO, N., RAAB, G.I., YUSUPOV, V. I., BIRBILIS, N., SALISHCHEV, G. and ESTRIN, Y. Strength, corrosion resistance, and biocompatibility of ultrafine-grained Mg alloys after different modes of severe plastic deformation. In 7th International Conference on Nanomaterials by Severe Plastic Deformation. 2017. DOI:10.1088/1757-899X/194/1/012004.

[4] TOFAIL, S. A. M., KOUMOULOS, E. P., BANDYOPADHYAY, A., BOSE, S., O'DONOGHUE, L. and CHARITIDIS, C. Additive manufacturing: scientific and technological challenges, market uptake and opportunities. Materials Today. 2018. vol. 21, no. 1, pp. 22-37.

[5] FOUSOVÁ, M., VOJTĚCH, D. and FOJT, J. Microscopic evaluation of 3D-printed materials surface and characteristic microstructure. Manufacturing Technology. 2016. vol. 16, no. 5, pp. 902-909.

[6] ZHENG, B., ZHOU, Y., SMUGERESKY, J. E. et. al. Thermal behavior and microstructure evolution during laser deposition with laser-engineered net shaping, Part II. Experimental investigation discussion. Metallurgical and Materials Transaction A. 2011. vol. 42, no. 10, pp. 3190-3199.

[7] POPOVICH, A., SUFIIAROV, V., BORISOV, E. and POLOZOV, I.: Microstructure and mechanical properties of Ti-6AI-4V manufactured by SLM. Key Engineering Materials. 2015. vols. 651-653, pp. 677-682, DOI: 10.4028/www.scientific.net/KEM.651-653.677

[8] FINE, M. E. and STRAKE, E. A.: Rapidly Solidified Powder Aluminum Alloys: A Symposium. 1986. ASTM, ISSN 0066_0558, (citation 8.5.2019), p. 544. online:

https://books.google.cz/books/about/Rapidly Solidified Powder Aluminum Alloy.html?id=JMRTAAAAMAAJ\&redi $\underline{\mathrm{r} \text { esc }=\mathrm{y}}$, 